\title{
Elastoplastic Analysis of Circular Openings in Elasto-Brittle-Plastic Rock Mass Based on Logarithmic Strain
}

\author{
Qiang Zhang, Cheng Li, Ming Min, Binsong Jiang, and Liyuan Yu \\ State Key Laboratory for Geomechanics and Deep Underground Engineering, School of Mechanics and Civil Engineering, \\ China University of Mining and Technology, Xuzhou 221116, China
}

Correspondence should be addressed to Binsong Jiang; jiangbs@cumt.edu.cn

Received 27 June 2017; Revised 21 October 2017; Accepted 7 November 2017; Published 11 December 2017

Academic Editor: Petr Krysl

Copyright (C) 2017 Qiang Zhang et al. This is an open access article distributed under the Creative Commons Attribution License, which permits unrestricted use, distribution, and reproduction in any medium, provided the original work is properly cited.

Rock-like materials, such as coal and soft rock, often manifest larger deformation features. The prediction values for displacement and failure region based on the commonly used small strain (SS) theory are generally larger than the field test results. Based on the Euler coordinate system, the logarithmic strain (LS) is employed to describe the actual deformation behavior. Both of the stresses and displacement of circular opening in elasto-brittle-plastic rock mass are formulated with differential equations. And a simple approach is proposed to solve the differential equations. The results show that the plastic radius depends on the elastic parameters, that is, Young's modulus and Poisson's ratio, which is different from SS theory. And the plastic radius and displacement of LS rock mass are smaller than those of SS rock mass, and the displacement of LS rock mass is absolutely smaller than the excavation radius. The proposed solutions can provide theoretical foundation for the optimization of supporting structure in underground engineering.

\section{Introduction}

Large deformation usually occurs in the deep underground engineering, and this often leads to stability problems. Considering the two basic factors of intrinsic material characters and stress environment condition, the main reasons for large deformation are as follows. (1) Surrounding rock mass is usually weakened, especially soft rock. And the creep displacement is usually significant with tens of millimeters every day. When the supporting intensity is not strong enough, the displacement even reaches tens of centimeters. The evidences are generally shown in forms of bottom cleaning and multirebuilding of surrounding rock. Although large deformation occurs, the surrounding rock still remains intact. (2) With the increasing depth of coal mine, the surrounding rock may fracture when the depth reaches a certain value, even though the surrounding rock has the same properties. Moreover, the lining structure may also fracture, which may cause instability problems. The main reason is the increasing in suit pressure, such as Liuhai coal mine, Huainan and Tiefa coal district. In this area, special enhanced lining structure is needed to avoid large deformation and to keep the surrounding rock stable.
Under this situation, rock mechanics problem of underground engineering becomes such an important research field to ensure the stability [1].

In recent years, lots of tests and engineering experiments have been carried out. The lining and reinforcement technology of the surrounding rock in high in situ pressure has been developed significantly. High-strength bolt (cable) and grouting technology can efficiently and effectively prevent the displacement and failure behavior of surrounding rock [2-6]. Unfortunately, the classical elastic-plastic theory is developed based on small strain (SS) theory, which cannot well reflect the actual large deformation condition [7-11]. So far, the deformation and failure mechanics, together with the behavior of reinforced surrounding rock, have not been revealed theoretically, which leads to the fact that the generally used numerical method cannot precisely predict the stress and displacement distribution law. Moreover, when Young's modulus is significantly small, the calculated displacement may be larger than the excavation radius, which is in conflict with the real condition. In view of this fact, logarithmic strain is employed to predict the tunnel contraction displacement with similarity methods for perfect elastoplastic rock 


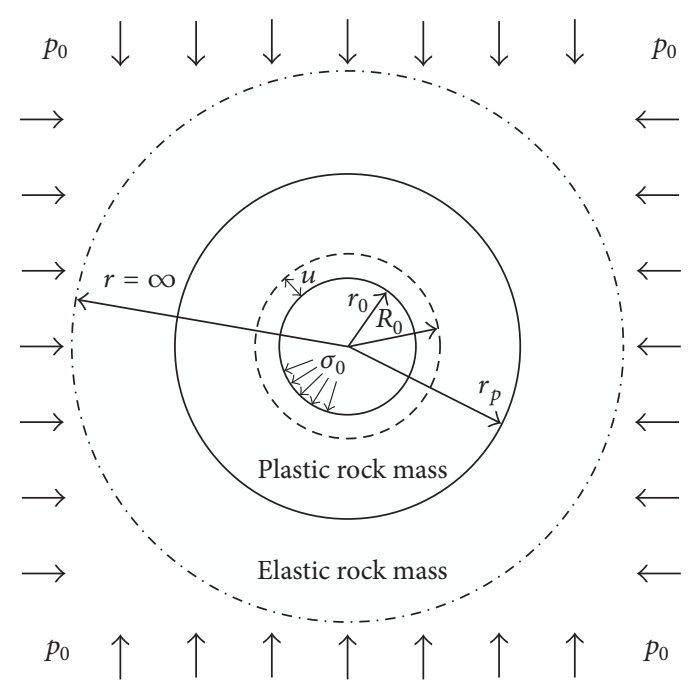

FIGURE 1: Calculated model of circular openings.

mass [12-14]. Unfortunately, the rock-like material generally manifests brittle failure behavior once its peak strength is reached.

In fact, the deformation theory can be classified as Lagrange and Euler space based on the definition of strain. For larger deformation condition, the particle moves with displacement, and this can be well described by the logarithmic strain (LS). Moreover, its description formulation is relatively simple and has a wide usage in solid mechanics $[15,16]$. However, it is rarely used in stress and displacement analysis for geotechnical engineering. According to the long circular openings subject to hydrostatic pressure, this paper mainly analyzed the stress and deformation characteristics based on LS theory.

\section{Basic Theory and Equations}

Figure 1 shows a long circular opening with radius $R_{0}$ excavated in a homogeneous, isotropic rock mass. The initial stress is subject to a hydrostatic stress $p_{0}$. Once the opening is excavated, a convergence displacement of the surrounding rock would occur immediately. Then the uniformed supporting pressure $\sigma_{0}$, which is provided by the lining structure, would act on the surrounding rock to keep its stability. Both the displacement and stress are gradually adjusted until a new balance state is reached with the final radius $r_{0}$.

In polar coordinates, the position of material point is $(R, \theta)$ in the original coordinate space before opening is excavated. After the opening is excavated, its position would be changed to $(r, \theta)$ with a radial displacement $u$ in the new deformation space. If the contraction displacement is defined as positive, the relation between the original and new position can be related as

$$
R=r+u
$$

For geotechnical engineering, large deformation generally occurs before macro failure happens, especially of the soft rock mass. In this condition, the small deformation theory cannot well describe the deformation behavior when the deformation is large. However, the Logarithmic strain, which is established on the real deformation, can well reflect the nonlinear large deformation [17]. And its geometric equation can be expressed as

$$
\begin{aligned}
& \varepsilon_{r}=\ln \left(\frac{\partial R}{\partial r}\right)=\ln \left(1+\frac{\partial u}{\partial r}\right), \\
& \varepsilon_{\theta}=\ln \left(\frac{R}{r}\right)=\ln \left(1+\frac{u}{r}\right),
\end{aligned}
$$

where $\varepsilon_{r}$ and $\varepsilon_{\theta}$ are the radial and tangential strain, respectively.

Once the displacement occurs, material point would finally reach another balance state. In this new coordinate, the equilibrium differential equation for axisymmetric problems can be expressed as (without considering the body force of rock mass)

$$
\frac{d \sigma_{r}}{d r}+\frac{\sigma_{r}-\sigma_{\theta}}{r}=0
$$

The difficulty of the plastic problem is induced by the plastic deformation. And the plastic deformation occurs once the stresses satisfy the yield criterion. The linear MohrCoulomb criterion is usually employed to describe the critical elastic state, and for the intact rock mass, it can be formulated as

$$
\begin{aligned}
& \sigma_{\theta}=\alpha \sigma_{r}+Y \quad \text { for intact rock mass, } \\
& \sigma_{\theta}=\alpha_{r} \sigma_{r}+Y_{r} \quad \text { for post-failure rock mass, }
\end{aligned}
$$

where $\alpha=(1+\sin \varphi) /(1-\sin \varphi), Y=2 c \cos \varphi /(1-\sin \varphi)$, $\alpha_{r}=\left(1+\sin \varphi_{r}\right) /\left(1-\sin \varphi_{r}\right), Y_{r}=2 c_{r} \cos \varphi_{r} /\left(1-\sin \varphi_{r}\right), \varphi$ and $c$ are the friction angle and cohesion of the intact rock mass, and $\varphi_{r}$ and $c_{r}$ are the friction angle and cohesion of the postfailure rock mass.

For the plastic rock mass, the plastic strain is governed by the plastic potential function. And the Mohr-Coulomb 
function is usually employed for the rock-like material. In regard to the circular opening, it can be formed as

$$
\Phi=\sigma_{\theta}-\beta \sigma_{r},
$$

where $\beta=(1+\sin \psi) /(1-\sin \psi)$ and $\psi$ is the dilation angle of the postfailure rock mass.

For a long opening, it can be regarded as the plane strain problem without axial displacement. The elastic rock mass obeys the generalized Hooke's law; meanwhile, the total strain of the plastic rock mass is composed of the elastic component and plastic component. Based on the plastic potential theory, the plastic strain depends on the plastic potential function of (5). In this way, the total strain induced by excavation can be uniformly expressed as

$$
\begin{aligned}
& \varepsilon_{r}=\frac{1}{2 G}\left[(1-v)\left(\sigma_{r}-p_{0}\right)-v\left(\sigma_{\theta}-p_{0}\right)\right]-\lambda \beta, \\
& \varepsilon_{\theta}=\frac{1}{2 G}\left[(1-v)\left(\sigma_{\theta}-p_{0}\right)-v\left(\sigma_{r}-p_{0}\right)\right]+\lambda,
\end{aligned}
$$

where $\sigma_{r}$ and $\sigma_{\theta}$ are the radial and tangential stresses, respectively, $G=E /[2(1+v)]$ is the shear modulus, and $E$ and $v$ are Young's modulus and Poisson's ratio, respectively. $\lambda$ is the plastic multiplier, and $\lambda=0$ for the elastic rock mass.

The boundary conditions of this problem can be described as

$$
\begin{aligned}
& \sigma_{r}=\sigma_{0} \quad\left(R=R_{0}\right), \\
& \sigma_{r p}=\sigma_{r e}, \\
& u_{r p}=u_{e} \\
& \quad\left(R=R_{p}\right), \\
& \sigma_{r}=p_{0} \quad(R \longrightarrow \infty),
\end{aligned}
$$

where $\sigma_{r e}$ and $\sigma_{r p}$ are the radial stress for elastic and plastic rock mass, respectively.

For SS model, the stresses, displacement, and plastic radius for both plastic and elastic rock mass can be easily obtained (the subscript " $S$ " denotes the small strain model), as shown in

$$
\begin{aligned}
R_{p}^{S} & =R_{0}\left[\frac{\left(p_{c}+B_{r}\right)}{\left(\sigma_{0}+B_{r}\right)}\right]^{1 /\left(\alpha_{r}-1\right)}, \\
\sigma_{r}^{S} & =A_{r}\left(\frac{r}{R_{0}}\right)^{\alpha_{r}-1}-B_{r}, \\
\sigma_{\theta}^{S} & =\alpha_{r} A_{r}\left(\frac{r}{R_{0}}\right)^{\alpha_{r}-1}-B_{r}, \\
u^{S} & =\frac{1}{2 G}\left[\eta A_{r}\left(\frac{r}{R_{0}}\right)^{\alpha_{r}-1}-T\left(\frac{R_{0}}{r}\right)^{\beta+1}\right. \\
& \left.-(1-2 v)\left(p_{0}+B_{r}\right)\right],
\end{aligned}
$$

$$
\begin{aligned}
& \sigma_{r}^{S}=p_{0}\left[1-\left(\frac{R_{p}^{S}}{r}\right)^{2}\right]+p_{c}\left(\frac{R_{p}^{S}}{r}\right)^{2}, \\
& \sigma_{\theta}^{S}=p_{0}\left[1+\left(\frac{R_{p}^{S}}{r}\right)^{2}\right]-p_{c}\left(\frac{R_{p}^{S}}{r}\right)^{2}, \\
& u^{S}=\frac{\left(p_{0}-p_{c}\right) R_{p}^{S 2}}{2 G r},
\end{aligned}
$$

$$
\left(r>R_{p}^{S}\right)
$$

where $\sigma_{r}^{S}$ and $\sigma_{\theta}^{S}$ are the radial and tangent stress, respectively, $u_{p}^{S}$ is the displacement, and $R_{p}^{S}$ is the plastic radius; $A_{r}=\sigma_{0}+$ $B_{r}, B_{r}=c_{r} \cot \varphi_{r}, \eta=(1-v)\left(1+\alpha_{r} \beta\right) /\left(\alpha_{r}-\beta\right)-v, T=$ $(1-\eta) A\left(R_{p} / R_{0}\right)^{\alpha-1}-2(1-v)\left(p_{0}+B\right), A=\sigma_{0}+B, B=c \cot \varphi$, $p_{c}=p_{0}(1+\sin \varphi)-c \cot \varphi$.

\section{Analytical Solutions}

3.1. Stress and Displacement of the Elastic Rock Mass. The strains $\varepsilon_{r}$ and $\varepsilon_{\theta}$ are all functions of displacement, as shown in (2). By submitting (1) into (2), the compatibility equation of deformation can be obtained as

$$
\frac{\partial \varepsilon_{\theta}}{\partial R}=\frac{1}{R}\left(1-e^{\varepsilon_{\theta}-\varepsilon_{r}}\right) .
$$

By submitting (2) into (6), the radial and tangent stress component can be formulated as

$$
\begin{aligned}
\sigma_{r}= & \frac{2 G}{1-2 v}\left[(1-v) \ln \left(1+\frac{\partial u}{\partial r}\right)+v \ln \left(1+\frac{u}{r}\right)\right] \\
& +p_{0}, \\
\sigma_{\theta}= & \frac{2 G}{1-2 v}\left[(1-v) \ln \left(1+\frac{u}{r}\right)+v \ln \left(1+\frac{\partial u}{\partial r}\right)\right] \\
& +p_{0} .
\end{aligned}
$$

By submitting (10) into (9), the compatibility equation can be expressed by stress as

$$
(1-v) \frac{\partial \sigma_{\theta}}{\partial R}-v \frac{\partial \sigma_{r}}{\partial R}=\frac{2 G}{R}\left[1-e^{\left(\sigma_{\theta}-\sigma_{r}\right) / 2 G}\right] .
$$

Using the relation between original and new coordinates of (1) and geometric equation of (2), the equilibrium differential equation of (3) can be rewritten in the original space as

$$
\frac{\partial \sigma_{r}}{\partial R}+\frac{\sigma_{r}-\sigma_{\theta}}{R} e^{\varepsilon_{\theta}-\varepsilon_{r}}=0 .
$$

Then by submitting the radial and tangent stress of (10) into the equilibrium differential equation of (12), the equilibrium differential equation can be expressed by stress component as

$$
\frac{\partial \sigma_{r}}{\partial R}+\frac{\sigma_{r}-\sigma_{\theta}}{R} e^{\left(\sigma_{\theta}-\sigma_{r}\right) / 2 G}=0 .
$$


As we all know, the stress is independent from Young's modulus $E$ and Poisson's ratio $v$ for SS model. However, (13) denotes that the elastic parameters influence the rock mass stress distribution form, and this is the main difference from the solutions based on the classic SS theory.

The displacement of rock mass can be calculated by submitting tangent strain of (6) into tangent geometric equation of (2). Then using the relation between the original and new coordinates system of (1), the displacement of elastic rock mass can be determined by

$$
u=R\left\{1-e^{-\left[(1-v)\left(\sigma_{\theta}-p_{0}\right)-v\left(\sigma_{r}-p_{0}\right)\right] / 2 G}\right\} .
$$

3.2. Stress and Displacement of the Plastic Rock Mass. In the postfailure region, the plastic rock mass satisfies the yield criterion of (4b). Similar to the elastic rock mass, the equilibrium differential equation of the plastic rock mass can be obtained by substituting (1), (2), (4b), and (10) into (3), as shown in

$$
\frac{\partial \sigma_{r}}{\partial R}-\frac{\left(\alpha_{r}-1\right) \sigma_{r}+Y_{r}}{R} e^{\left[\left(\alpha_{r}-1\right) \sigma_{r}+Y_{r}\right] / 2 G+(1+\beta) \lambda}=0 .
$$

The plastic strain should also satisfy the compatibility equation of deformation. By using the constitutive equation of (6), yield criterion of (4b), and geometric equation of (2), the compatibility equation of plastic rock mass can also be expressed in a differential form as

$$
\begin{aligned}
\frac{\partial \lambda}{\partial R} & +\frac{\left(\alpha_{r}-\alpha_{r} v-v\right)\left[\left(\alpha_{r}-1\right) \sigma_{r}+Y_{r}\right]}{2 G R} \\
& \cdot e^{\left[\left(\alpha_{r}-1\right) \sigma_{r}+Y_{r}\right] / 2 G+(1+\beta) \lambda} \\
& -\frac{1}{R}\left[1-e^{\left[\left(\alpha_{r}-1\right) \sigma_{r}+Y_{r}\right] / 2 G+(1+\beta) \lambda}\right]=0 .
\end{aligned}
$$

By using the geometric equation, the displacement of plastic rock mass can be easily obtained as

$$
u=R\left\{1-e^{-\left[(1-v)\left(\sigma_{\theta}-p_{0}\right)-v\left(\sigma_{r}-p_{0}\right)\right] / 2 G-\lambda}\right\} .
$$

3.3. Calculation for Stress and Displacement. So far, all of the expressions of stresses and displacement have been derived. Theoretically speaking, the plastic radius $R_{p}$ can be obtained by using the peak yield criterion. Unfortunately, the stresses are all expressed in a differential form. In order to obtain the solutions, a simple numerical procedure is compiled to solve the differential equations.

The boundary conditions of (7) show that the displacement at $R=R_{p}$ should be continuous. Moreover, the elastic stress of the elastic rock mass at the elastoplastic boundary should satisfy the peak yield criterion. So, using the displacement of elastic and plastic rock mass, the plastic strain at $R=R_{p}$ can be determined as

$$
\lambda=\frac{(1-v)\left[\left(\alpha-\alpha_{r}\right) \sigma_{p}+Y-Y_{r}\right]}{(2 G)}
$$

where $\sigma_{p}$ is the radial stress at $R=R_{p}$.
For the elastic rock mass, the stress can be theoretically obtained with Runge-Kutta method with the boundary conditions of (7) by combining the differential equations of (11) and (13). However, the boundary conditions are only formulated by radial stress at $R=R_{p}$ and $R \rightarrow \infty$, and the plastic radius $R_{p}$ is still unknown. Based on Saint-Venant's principle, $\sigma_{r}$ tends to be $p_{0}$ when radius $R$ is large enough. In this paper, a significantly large radius $R=1000 R_{0}$ is employed to represent the undisturbed rock mass. In order to obtain the solutions, the values of plastic radius $R_{p}^{\prime}$ and stress state $\left(p_{0}, \sigma_{\theta}^{\prime}\right)$ at $R=1000 R_{0}$ are given. Then, the stresses can be recursively calculated from $1000 R_{0}$ to $R_{p}^{\prime}$ by (11) and (13). If the calculated stress at $R=R_{p}^{\prime}$ satisfies the peak yield criterion of (4a), the solutions would be correct. Otherwise, the tangent stress at $R=1000 R_{0}$ is updated with dichotomy, and the above steps are repeated. Similarly, the stresses and plastic strain can be obtained by substituting the initial value of radial stress and plastic strain at $R=R_{p}^{\prime}$, which are provided by the elastic solutions and (18), respectively, into (15) and (16). If the calculated radial stress at $R=R_{0}$ equals the actual value $\sigma_{0}$, the assumed plastic radius $R_{p}^{\prime}$ would be corrected, or the radius $R_{p}^{\prime}$ can be updated with dichotomy. The displacement can be obtained by substituting the stresses and plastic components into (14) and (17) for elastic and plastic rock mass, respectively. A detailed flowchart of the implementation is shown in Figure 2.

\section{Examples}

4.1. Verifications for Perfect Elastoplastic Rock Mass. The large strain problems for the perfect elastoplastic rock mass have been studied by Park and Vrakas. One group of these data is employed in this section to validate the proposed solution. Moreover, the numerical solutions are also calculated using finite differential method by FLAC3D. The calculated results are shown in Figure 3. When the dilation angle $\psi=20^{\circ}$, the calculated dimensionless displacements $u_{0} / R_{0}$ are 0.0548 , 0.0551, and 0.0551 for FDM, similarity, and this paper, respectively. And when the dilation angle $\psi=40^{\circ}$, the calculated dimensionless displacements based on the above three methods are $0.0619,0.0622$, and 0.0622 , respectively. So, the results of the proposed method are in agreement with both of the similarity solution and numerical results by FLAC3D.

4.2. Example for Elastic Rock Mass. A circular opening of radius $R_{0}=1.0$ excavated in elastic rock mass subject to a hydrostatic pressure $p_{0}=1.0 \mathrm{MPa}$ is studied. A wide range of Young's modulus $E=0.2 p_{0} \sim 10.0 p_{0}$ and Poisson's ratio $v=$ $0.001 \sim 0.499$ is considered. Figures 4 and 5 show the influence of Young's modulus and Poisson's ratio on the concentration factor $\left(\sigma_{t} / p_{0}\right)$ and dimensionless displacement, respectively. Obviously, the concentration factor of LS rock mass is smaller than that of SS rock mass, whose concentration factor is a constant value of 2.0. With the decrease of Young's modulus and the increase of Poisson's ratio, the concentration factor gradually decreases. And the limit concentration factor is 2.0 


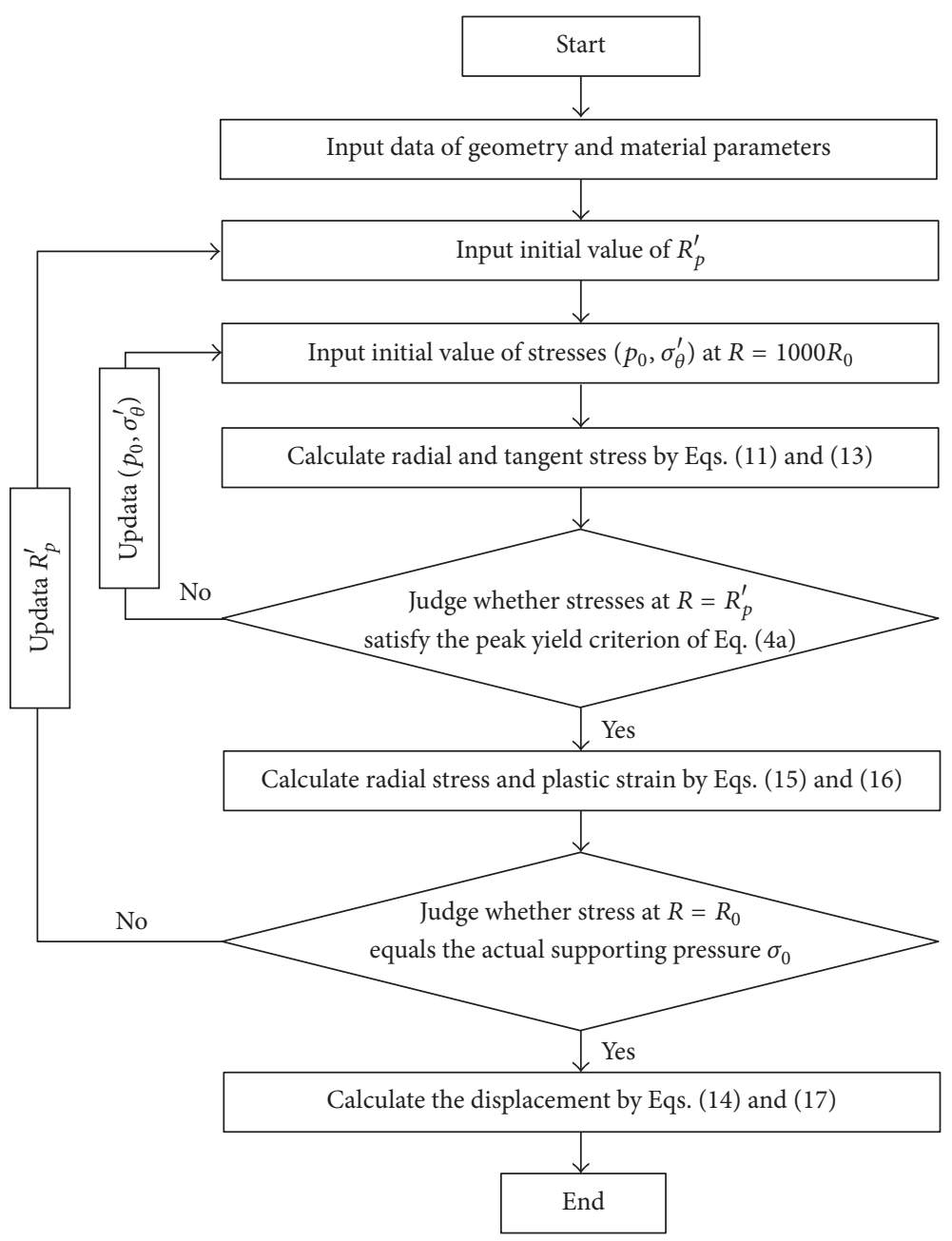

Figure 2: Flowchart of the implementation.

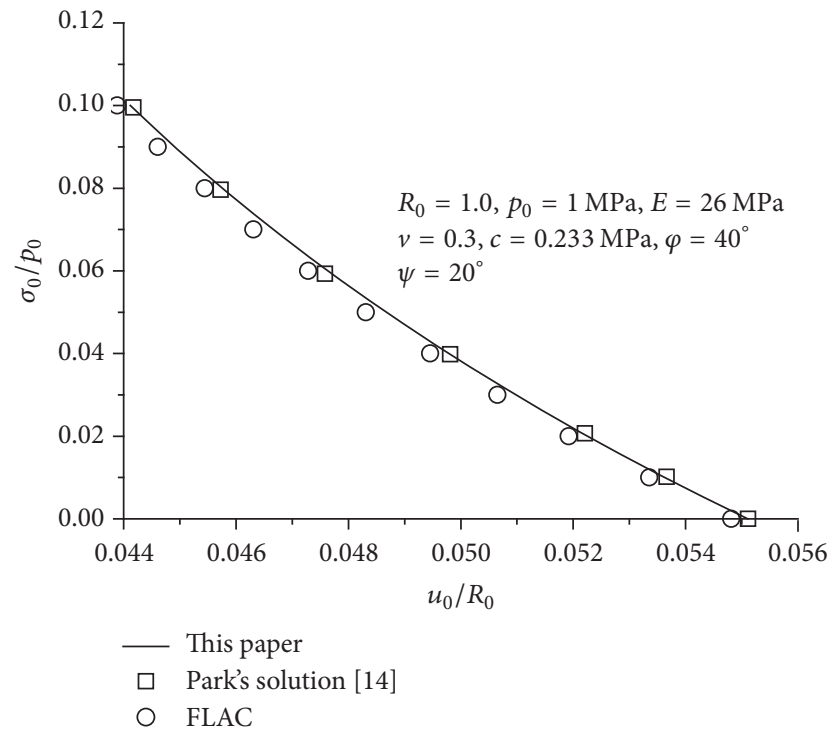

(a)

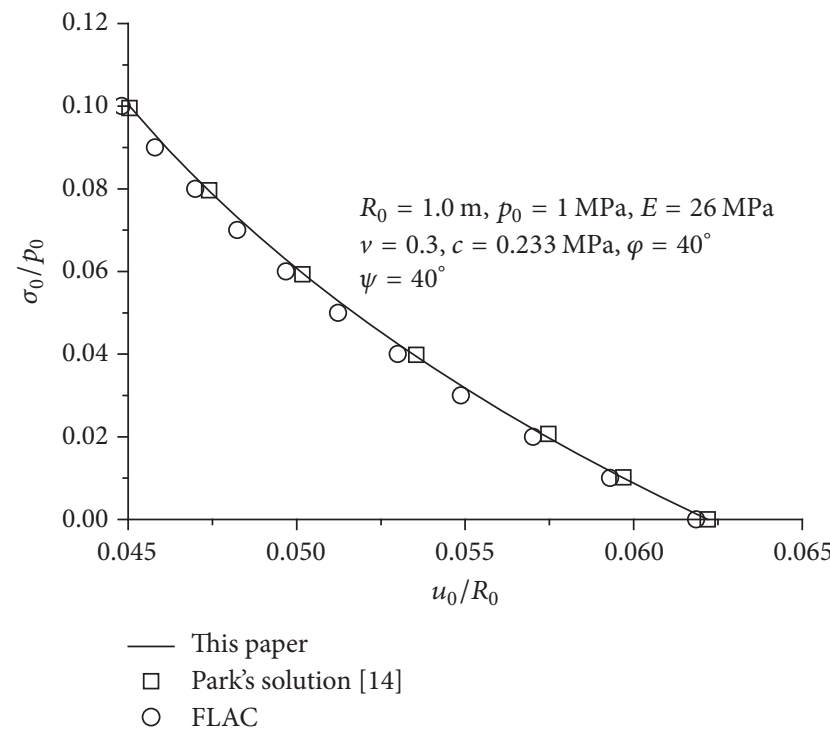

(b)

FIgURE 3: Comparison of ground response curves: (a) data set 1-1 and (b) data set 1-2. 


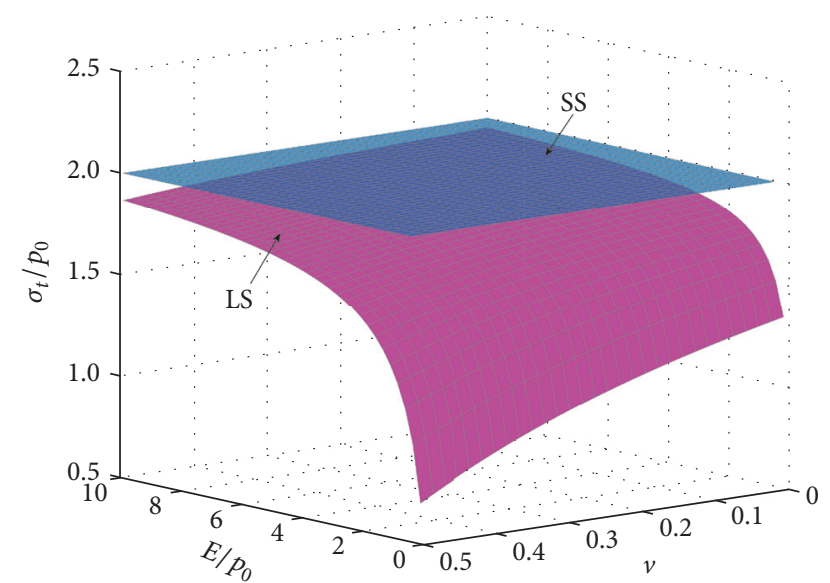

FIgURE 4: Influence of Young's modulus and Poisson's ratio on concentration coefficient.

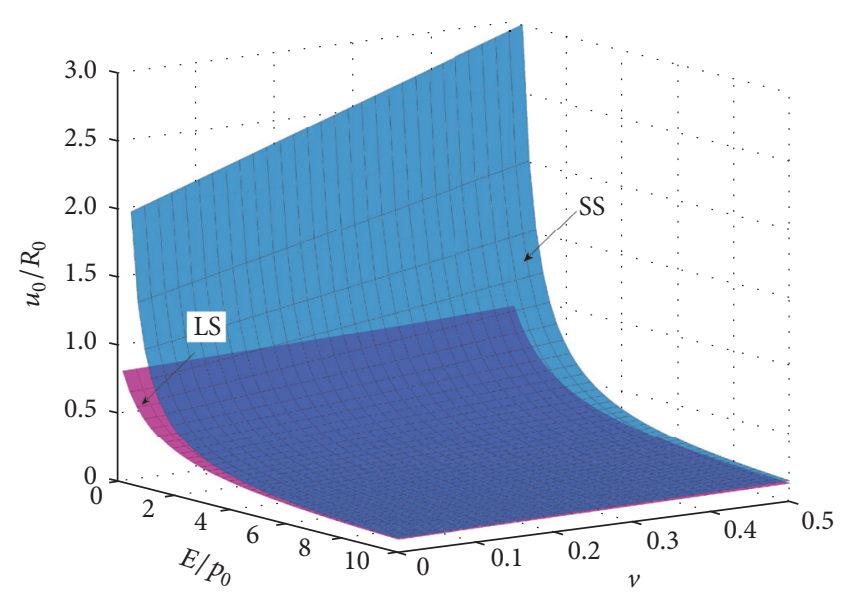

FIgURE 5: Influence of Young's modulus and Poisson's ratio on dimensionless displacement.

when Young's modulus is larger enough. In this case, the minimum concentration factor is 0.694 , which is only $34.7 \%$ of SS rock mass. Young's modulus and Poisson's ratio have almost the same effect on the dimensionless displacement as concentration factor. The dimensionless displacement $u_{0} E /\left(p_{0} R_{0}\right)$ of the excavation surface reaches its maximum value of $0.924 R_{0}$ when $E=0.2 p_{0}$ and $v=0.499$. Similarly, for the SS rock mass, the dimensionless displacement linearly increases with $G^{-1}$. In this case, the maximum displacement reaches $2.998 R_{0}$, which is larger than the excavation radius, when $E=0.2 p_{0}$ and $v=0.499$. In fact, this condition would never occur. This also indicates that the SS would lead to significant error results, especially for the soft rock mass.

4.3. Example for Elasto-Brittle-Plastic Rock Mass. The typical examples for kinds of Mohr-Coulomb rock mass, whose material properties are listed in Table $1[18,19]$, are analyzed to illustrate the difference between SS and LS plastic rock mass. And two sets of dilation angle $\psi=0^{\circ}$ and $30^{\circ}$ are considered. Table 2 shows the calculated plastic radius and dimensionless displacement for both SS and LS rock mass. The results show
TABLE 1: Geometry and material property parameters.

\begin{tabular}{lcc}
\hline Types of rock & Hard rock & Soft rock \\
\hline $\begin{array}{l}\text { Radius of opening, } R_{0} \\
(\mathrm{~m})\end{array}$ & 1 & 1 \\
$\begin{array}{l}\text { Initial stress, } p_{0} \\
\text { (MPa) }\end{array}$ & 1 & 1 \\
$\begin{array}{l}\text { Supporting pressure, } \\
\sigma_{0}(\mathrm{MPa})\end{array}$ & 0 & 0 \\
Young's modulus, $E$ & 50 & 5 \\
$(\mathrm{GPa})$ & & \\
Poisson ratio, $v(-)$ & 0.2 & 0.2 \\
$\begin{array}{l}\text { Dilation angle, } \psi \\
\text { (Deg) }\end{array}$ & 0,30 & 0,30 \\
$c(\mathrm{MPa})$ & 0.173 & 0.276 \\
$\varphi(\mathrm{Deg})$ & 55 & 35 \\
$c_{r}(\mathrm{MPa})$ & 0.061 & 0.055 \\
$\varphi_{r}(\mathrm{Deg})$ & 52 & 30 \\
\hline
\end{tabular}

that the plastic region and displacement of LS are not larger than SS. For the LS rock mass, a slight decrease of plastic radius occurs when the dilation angle changes from $0^{\circ}$ to $30^{\circ}$ for the soft rock mass. However, the dilation angle does not have influence on the plastic radius for SS rock mass, whose plastic radius only depends on the mechanical properties and hydrostatic pressure. For the hard rock mass, the solutions of SS and LS are similar. However, for the soft rock mass, the plastic radius and displacement of LS are smaller than SS. This also indicates that the SS model is only suitable for hard rock, whose displacement is smaller enough. And the prediction displacement and plastic radius would be larger than real condition for soft rock.

A series of Young's modulus and Poisson's ratio is employed to illustrate their influence on stresses and dimensionless displacement. The calculated results are shown in Table 3 and Figures 6-8. The results denote that both of the plastic radius and dimensionless displacement at $R=R_{0}$ gradually increase with the decreasing of Young's modulus for LS rock mass. When Young's modulus changes from $5000 p_{0}$ to $p_{0}$, the dimensionless plastic radius $R_{p} / R_{0}$ and displacement $u_{0} E /\left(p_{0} R_{0}\right)$ increase by $0.136 R_{0}(13.54 \%)$ and 0.998 (175.17\%), respectively. When Poisson's ratio changes from 0.001 to 0.499 , only a slight increase of $0.403 R_{0}$ of dimensionless displacement $u_{0} E /\left(p_{0} R_{0}\right)$ occurs. However, for the SS rock mass, Young's modulus does not have any influence on the dimensionless plastic radius and displacement, and the increasing Poisson's ratio only enlarges the displacement slightly. Therefore, Young's modulus has a more significant influence on plastic radius and displacement for LS rock mass, especially for soft rock mass. The common calculated plastic radius and displacement based on SS theory are generally larger than the actual field test results, and the difference becomes much bigger for the soft rock mass. However, the plastic radius and dimensionless displacement of the proposed solutions depend on Young's modulus, and they all significantly increase with the decreasing Young's modulus. And the dimensionless displacement increases with 
TABLE 2: Geometry and material property parameters.

\begin{tabular}{|c|c|c|c|c|c|}
\hline \multirow{2}{*}{ Rock mass } & \multirow{2}{*}{ Calculation scheme } & \multicolumn{2}{|c|}{ LS } & \multicolumn{2}{|c|}{ SS } \\
\hline & & $R_{p} / R_{0}$ & $u_{0} E /\left(p_{0} R_{0}\right)$ & $R_{p} / R_{0}$ & $u_{0} E /\left(p_{0} R_{0}\right)$ \\
\hline \multirow{4}{*}{ Hard rock } & $\operatorname{ebp}\left(\psi=0^{\circ}\right)$ & 1.1436 & 1.5682 & 1.1437 & 1.5863 \\
\hline & $\operatorname{ebp}\left(\psi=30^{\circ}\right)$ & 1.1436 & 2.0381 & 1.1437 & 2.0799 \\
\hline & ep $\left(\psi=0^{\circ}\right)$ & 1.0585 & 1.2556 & 1.0585 & 1.2557 \\
\hline & ep $\left(\psi=30^{\circ}\right)$ & 1.0585 & 1.3159 & 1.0585 & 1.3159 \\
\hline \multirow{4}{*}{ Soft rock } & $\operatorname{ebp}\left(\psi=0^{\circ}\right)$ & 1.7604 & 3.9731 & 1.7615 & 4.0442 \\
\hline & $\operatorname{ebp}\left(\psi=30^{\circ}\right)$ & 1.7576 & 11.9596 & 1.7615 & 12.3030 \\
\hline & $\mathrm{ep}\left(\psi=0^{\circ}\right)$ & 1.1649 & 1.3635 & 1.1650 & 1.3640 \\
\hline & $\mathrm{ep}\left(\psi=30^{\circ}\right)$ & 1.1649 & 1.5666 & 1.1650 & 1.5674 \\
\hline
\end{tabular}

Note. "ebp" means elastic-brittle-plastic model and "ep" means ideal elastoplastic model.

TABLE 3: Calculated results with different elastic parameters for LS and SS rock mass.

\begin{tabular}{|c|c|c|c|c|c|}
\hline \multirow{2}{*}{ Rock mass } & \multirow{2}{*}{ Calculation scheme } & \multicolumn{2}{|c|}{ LS } & \multicolumn{2}{|c|}{ SS } \\
\hline & & $R_{p} / R_{0}$ & $u_{0} E /\left(p_{0} R_{0}\right)$ & $R_{p} / R_{0}$ & $u_{0} E /\left(p_{0} R_{0}\right)$ \\
\hline \multirow{5}{*}{$\begin{array}{l}\text { Hard rock } \\
v=0.2 \\
\psi=0^{\circ}\end{array}$} & $E=1 \mathrm{MPa}$ & 1.0072 & 0.5699 & 1.1437 & 1.5863 \\
\hline & $E=4 \mathrm{MPa}$ & 1.0575 & 1.0688 & 1.1437 & 1.5863 \\
\hline & $E=7 \mathrm{MPa}$ & 1.0829 & 1.2333 & 1.1437 & 1.5863 \\
\hline & $E=20 \mathrm{MPa}$ & 1.1173 & 1.4299 & 1.1437 & 1.5863 \\
\hline & $E=50.0 \mathrm{GPa}$ & 1.1436 & 1.5682 & 1.1437 & 1.5863 \\
\hline \multirow{5}{*}{$\begin{array}{l}\text { Hard rock } \\
E=50 \mathrm{GPa} \\
\psi=0^{\circ}\end{array}$} & $v=0.001$ & 1.1436 & 1.3845 & 1.1437 & 1.4034 \\
\hline & $v=0.1$ & 1.1436 & 1.4797 & 1.1437 & 1.4984 \\
\hline & $v=0.2$ & 1.1436 & 1.5682 & 1.1437 & 1.5863 \\
\hline & $v=0.35$ & 1.1436 & 1.6865 & 1.1437 & 1.7031 \\
\hline & $v=0.499$ & 1.1436 & 1.7870 & 1.1437 & 1.8017 \\
\hline
\end{tabular}

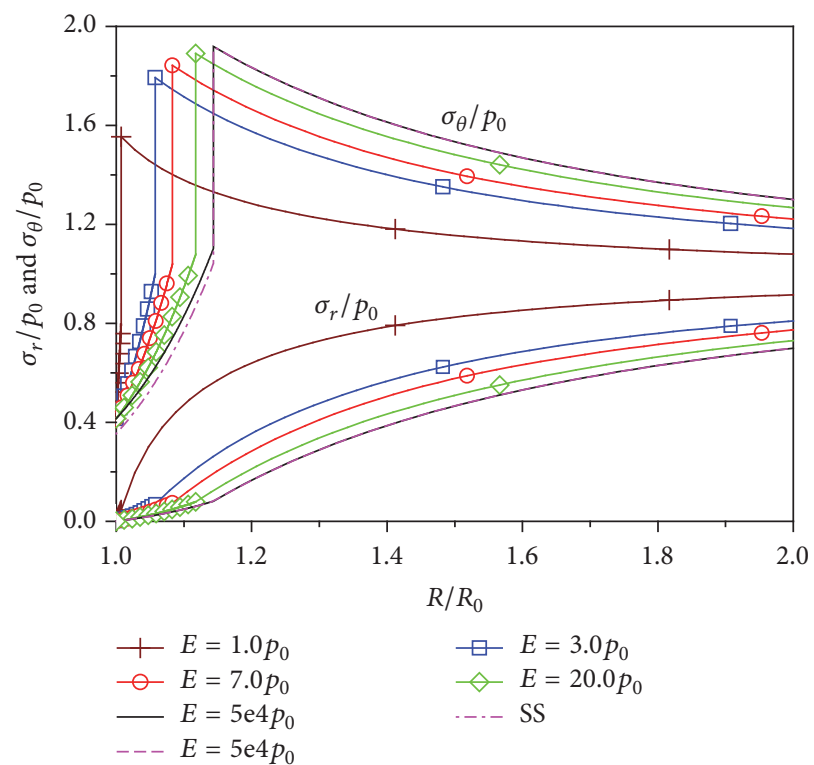

FIGURE 6: Influence of Young's modulus on stresses distribution. 


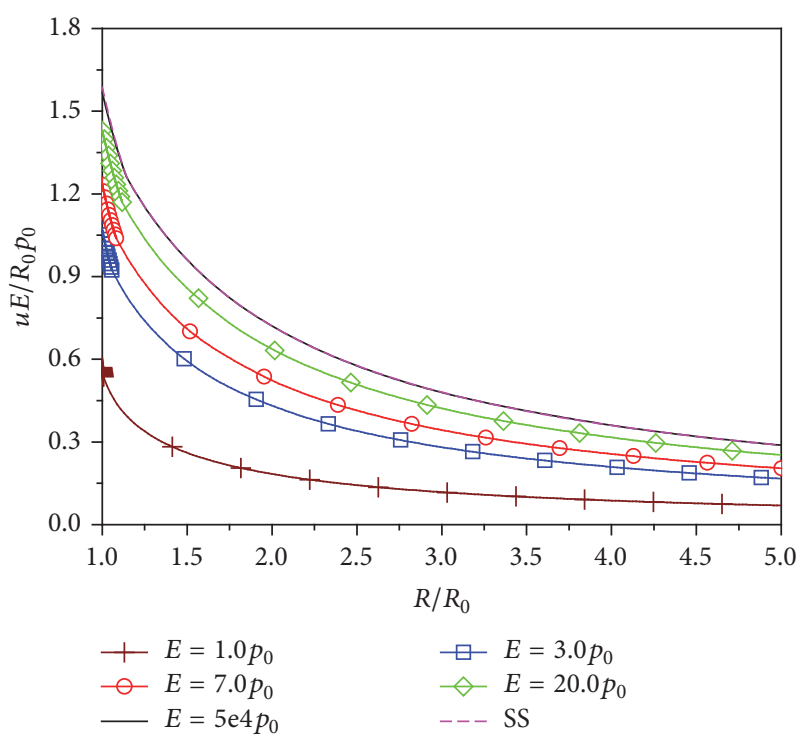

Figure 7: Influence of Young's modulus on dimensionless displacement.

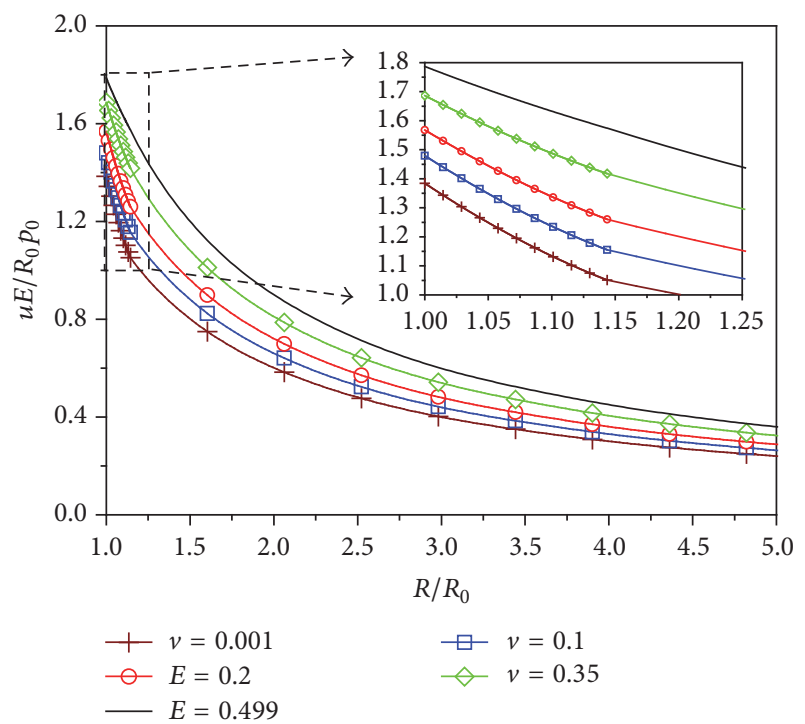

Figure 8: Influence of Poisson's ratio on dimensionless displacement.

the increasing Poisson's ratio. Moreover, the displacement would be less than the excavation radius under any condition. Therefore, the LS theory is much more reasonable for the rock-like material, especially for soft rock mass.

\section{Conclusions}

Based on the logarithmic strain theory, the differential equations for stress and displacement of circular opening excavated in elasto-brittle-plastic rock mass are deduced, and a simple approach is proposed to solve the differential equations. The calculated plastic radius and displacement of LS rock mass are smaller than those of SS rock mass. For the LS rock mas, the concentration factor significantly increases, especially for the soft rock mass, with the decrease of Young's modulus and the increase of Poisson's ratio. And the limit value of concentration factor of LS rock mass is 2.0. Both of the plastic radius and dimensionless displacement are dependent on Young's modulus and Poisson's ratio. With the decrease of Young's modulus and the increase of Poisson's ratio, the plastic radius and dimensionless displacement increase. But Young's modulus does not have any influence on the plastic radius and dimensionless displacement for the SS rock mass. For most of the underground engineering, the calculated plastic radius based on SS theory is larger than the actual test value. And the displacement may be larger than the excavation radius, which does not satisfy the real condition. In this way, the proposed method can better predict the failure and deformation characters for soft and fracture rock mass.

\section{Conflicts of Interest}

The authors declare that there are no conflicts of interest regarding the publication of this paper.

\section{Acknowledgments}

This project is supported by the National Basic Research 973 Program of China (2014CB046306), the National Natural Science Foundation of China (nos. 51204168 and 51579239) and the Fundamental Research Funds for the Central Universities (2012QNB23).

\section{References}

[1] M.-C. He, H.-P. Xie, S.-P. Peng, and Y.-D. Jiang, "Study on rock mechanics in deep mining engineering," Chinese Journal of Rock Mechanics and Engineering, vol. 24, no. 16, pp. 2803-2813, 2005 (Chinese).

[2] Y. Jiang, H. Wang, Y. Zhao, C. Liu, and X. Zhu, "Study of complementary supporting technology of extremely soft rock mining roadway," Chinese Journal of Rock Mechanics and Engineering, vol. 28, no. 12, pp. 2383-2390, 2009.

[3] H.-Y. Li and S.-C. Li, "Study and application of support technology on swelling soft rock roadway," Journal of the China Coal Society, vol. 34, no. 3, pp. 325-328, 2009.

[4] M. He, X. Chen, G. Liang, H. Qian, Y. Zhou, and X. Zhuang, "Software system for large deformation mechanical analysis of soft rock engineering at great depth," Chinese Journal of Rock Mechanics and Engineering, vol. 26, no. 5, pp. 934-943, 2007.

[5] C. C. Li, "Rock support design based on the concept of pressure arch," International Journal of Rock Mechanics and Mining Sciences, vol. 43, no. 7, pp. 1083-1090, 2006.

[6] W. Lawrence, "A method for the design of longwall gateroad roof support," International Journal of Rock Mechanics and Mining Sciences, vol. 46, no. 4, pp. 789-795, 2009.

[7] W. Fan, M. Yu, L. Chen, and P. Sun, "Unified elastoplastic solution for surrounding rocks of openings with consideration of material dilatancy and softening," Chinese Journal of Rock Mechanics and Engineering, vol. 23, no. 19, pp. 3213-3220, 2004.

[8] Y. Pan and Z.-Q. Wang, "Elasto-plastic analysis on surrounding rock of circular chamber based on strain nonlinear softening," 
Chinese Journal of Rock Mechanics and Engineering, vol. 24, no. 6, pp. 915-920, 2005.

[9] B. Jiang, Q. Zhang, Y. He, and L. Han, "Elasto-plastic analysis of cracked surrounding rocks in deep circular openings," Chinese Journal of Rock Mechanics and Engineering, vol. 26, pp. 982-986, 2007 (Chinese).

[10] S. K. Sharan, "Exact and approximate solutions for displacements around circular openings in elastic-brittle-plastic HoekBrown rock," International Journal of Rock Mechanics and Mining Sciences, vol. 42, no. 4, pp. 542-549, 2005.

[11] K.-H. Park and Y.-J. Kim, "Analytical solution for a circular opening in an elastic-brittle-plastic rock," International Journal of Rock Mechanics and Mining Sciences, vol. 43, no. 4, pp. 616622, 2006.

[12] A. Vrakas and G. Anagnostou, "A finite strain closed-form solution for the elastoplastic ground response curve in tunnelling," International Journal for Numerical and Analytical Methods in Geomechanics, vol. 38, no. 11, pp. 1131-1148, 2014.

[13] A. Vrakas, "A finite strain solution for the elastoplastic ground response curve in tunnelling: rocks with non-linear failure envelopes," International Journal for Numerical and Analytical Methods in Geomechanics, vol. 41, no. 7, pp. 1077-1090, 2016.

[14] K. H. Park, "Large strain similarity solution for a spherical or circular opening excavated in elastic-perfectly plastic media," International Journal for Numerical and Analytical Methods in Geomechanics, vol. 39, no. 7, pp. 724-737, 2015.

[15] X. Liu, M. Li, and W. Huang, "Finite deformation elasto-plastic theory based on logarithmic strain and consistent algorithm," Acta Mechanica Solida Sinica, vol. 23, pp. 24-33, 2002.

[16] Z. Wang and G. Dui, "Approximate Formulae of the logarithmic strain tensor," Science Technology and Engineering, vol. 9, pp. 3421-3424, 2009.

[17] K. Heiduschke, "Computational aspects of the logarithmic strain space description," International Journal of Solids and Structures, vol. 33, no. 5, pp. 747-760, 1996.

[18] S. Wang and S. Yin, "A closed-form solution for a spherical cavity in the elastic-brittle-plastic medium," Tunnelling and Underground Space Technology, vol. 26, no. 1, pp. 236-241, 2011.

[19] Q. Zhang, B.-S. Jiang, S.-L. Wang, X.-R. Ge, and H.-Q. Zhang, "Elasto-plastic analysis of a circular opening in strain-softening rock mass," International Journal of Rock Mechanics and Mining Sciences, vol. 50, pp. 38-46, 2012. 


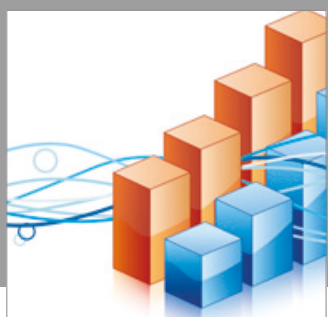

Advances in

Operations Research

vatersals

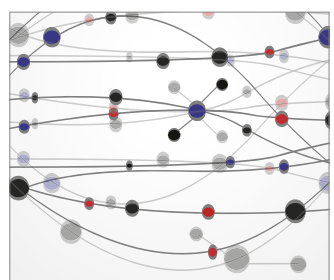

\section{The Scientific} World Journal
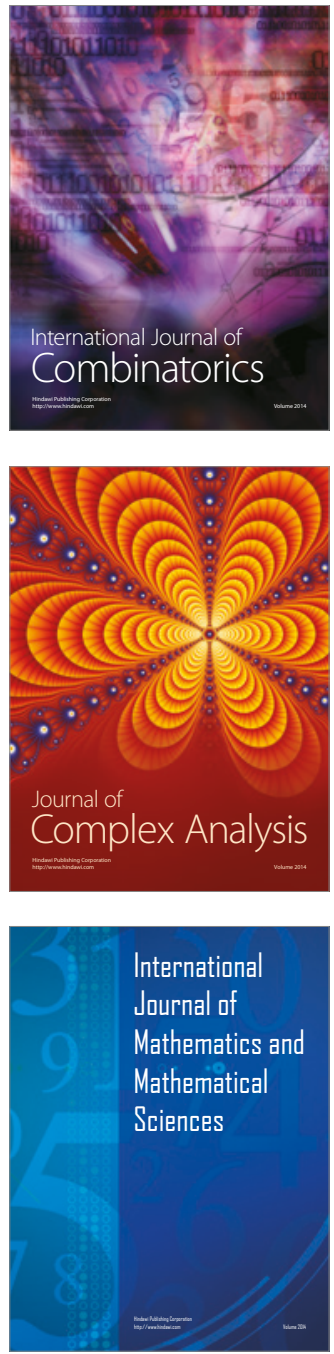
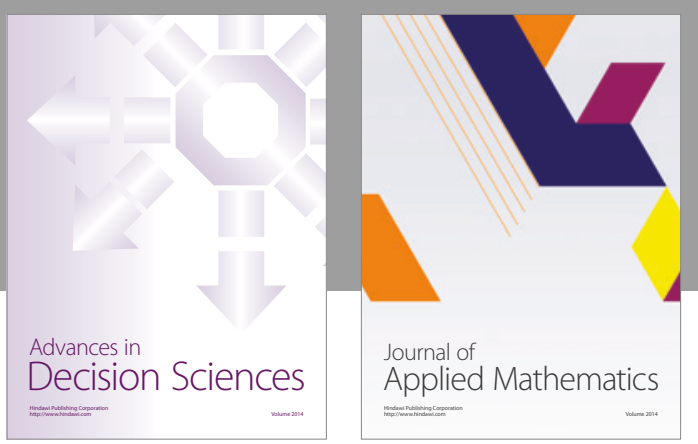

Algebra

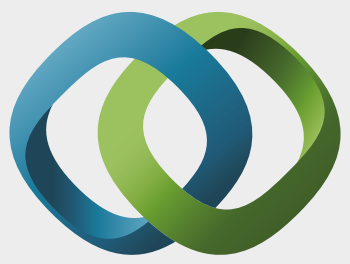

\section{Hindawi}

Submit your manuscripts at

https://www.hindawi.com
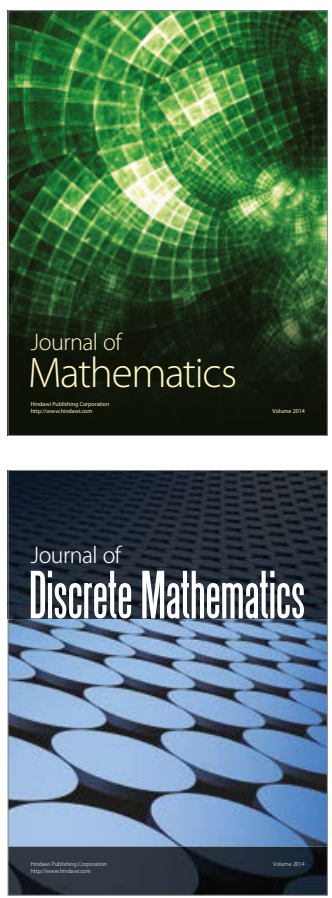

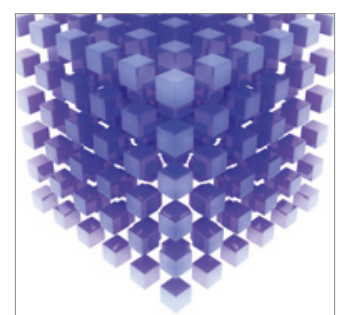

Mathematical Problems in Engineering
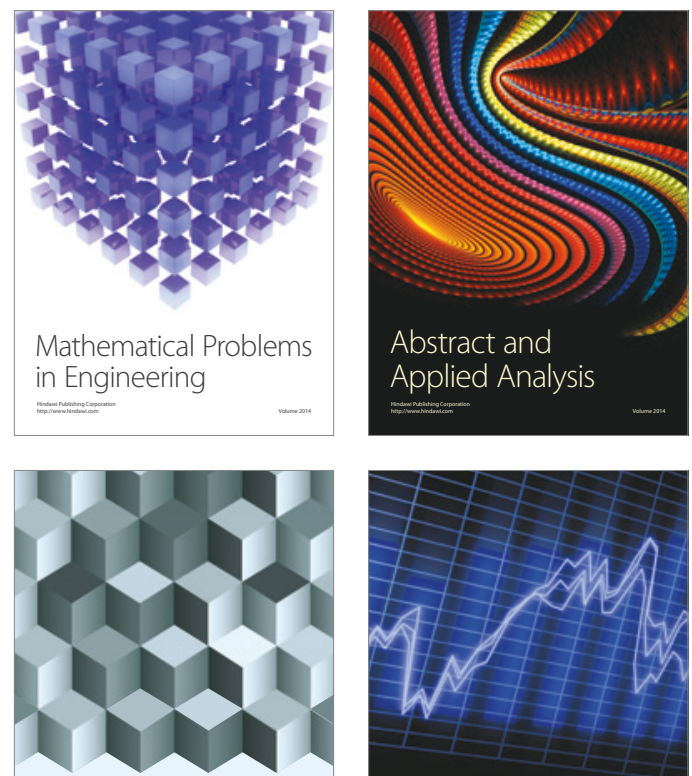

Journal of

Function Spaces

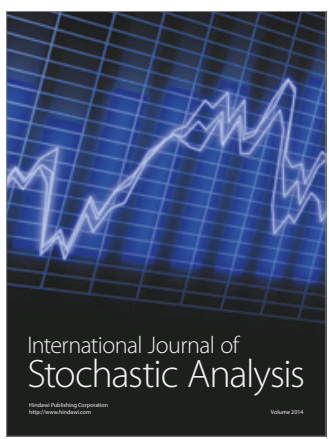

Probability and Statistics
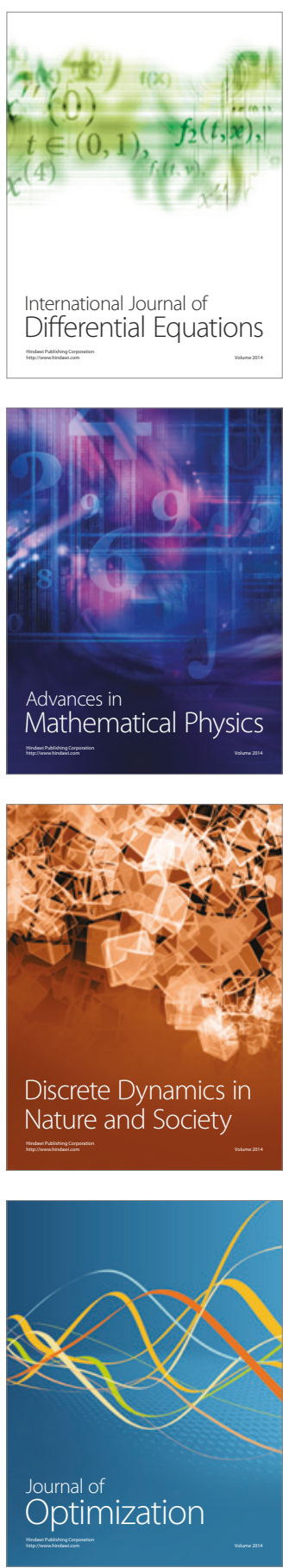